\title{
A retrospective analysis of mid trimester termination of pregnancies for fetal congenital malformations at tertiary care hospital
}

\section{Geethalakshmi Suriyanarayanan, Vijayalakshmi Kandasamy*, Anuradha Coimbatore Ramachandran}

Department of Obstetrics and Gynecology, Chettinad Hospital and Research Institute Kelambakkam, Chengalpattu district, Tamil Nadu, India

Received: 02 September 2021

Accepted: 30 September 2021

\section{*Correspondence:}

Dr. Vijayalakshmi Kandasamy,

E-mail: viji_kands@yahoo.co.in

Copyright: ( ) the author(s), publisher and licensee Medip Academy. This is an open-access article distributed under the terms of the Creative Commons Attribution Non-Commercial License, which permits unrestricted non-commercial use, distribution, and reproduction in any medium, provided the original work is properly cited.

\begin{abstract}
Background: This study was conducted to analyse the spectrum of fetal anomalies as a cause of pregnancy termination in a tertiary care hospital.

Methods: This retrospective study includes antenatal women with fetal anomalies diagnosed by an ultrasound (USG) and admitted in Chettinad Hospital and Research Institute, Kelambakkam from January 2018 to January 2020 for termination of pregnancy. Data was collected from hospital records and analysed.

Results: Gestational age of women with fetal congenital anomalies ranged from 13 to 21 weeks. Pregnancy termination, was performed between 17-19 weeks of gestation in 41\% of patients, between 13-15 weeks and 19-21 weeks in $23 \%$ of women respectively. Congenital fetal anomalies resulting in termination of pregnancy were CNS, musculoskeletal, cardiovascular, renal and multiple anomalies. CNS abnormalities was a major cause of termination of pregnancy which includes meningomyelocele, spina bifida, acrania, anencephaly.

Conclusions: In our study conducted at our tertiary care center, CNS abnormalities were the major cause of mid trimester termination of pregnancies, followed by musculoskeletal abnormalities being second most common cause.
\end{abstract}

Keywords: Congenital anomalies, Fetal, Pregnancy termination, Second trimester, Ultrasound

\section{INTRODUCTION}

Birth defects are most important cause of neonatal morbidity and mortality. Congenital fetal abnormalities lead to permanent disabilities and form a major health burden. About $3 \%$ of pregnancies are affected either by genetic or structural fetal anomaly. ${ }^{1}$

Increased incidence of fetal anomalies has led to prenatal diagnosis and screening tests to identify them and provide appropriate counselling and management. These defects are of prenatal origin resulting in intrinsic abnormalities or defective embryogenesis in the process of development. Birth defects can be a part of a syndrome or isolated abnormalities causing neonatal and infant morbidity and mortality. $^{2}$
According to NICE guidelines anomaly scan is routinely performed between 18 to 20 weeks of gestation. ${ }^{3}$ Most women diagnosed with fetal anomalies preferred to terminate the pregnancy with proportions ranging from $47 \%$ to $90 \% .^{4}$ Termination of pregnancy is performed as early and late, early pregnancy termination is carried out before 20 weeks of gestation and late after 24 weeks. ${ }^{5}$ Risk of complication increases with late pregnancy termination. Ultrasound is a non-invasive technique available to detect any congenital anomalies in pregnant woman, which will help to identify the single or multiple defects. It also gives physicians an opportunity for fetal therapy or better postnatal care.

Data from UK and Canada suggest that improved diagnosis during pregnancy has increased the rate of 
pregnancy termination for fetal anomalies. ${ }^{6}$ The present retrospective analysis has been conducted to evaluate the spectrum of structural fetal anomalies leading to termination of pregnancies and to ascertain the various socio demographic aspects. It will help us understand better and reduce the related maternal morbidity and mortality.

\section{METHODS}

A retrospective review of patients who underwent mid trimester pregnancy termination at Chettinad Hospital and Research Institute, from January 2018 to January 2020. Among the study group following factors like age, type of anomaly, gestational age at which fetal anomaly was diagnosed by ultrasound, method of termination of pregnancy and gender of fetus was collected and analysed.

Institutional Ethical Committee approval was obtained for this study. The data collected were analysed using SPSS package.

Routine antenatal check up with USG was performed on all pregnant women between 18 to 20 weeks of gestation. As soon as the diagnosis of fetal abnormality was confirmed through USG, pediatric surgeon's opinion taken for the prognosis of the fetus if born alive. After knowing the fetal anomaly counselling for the couple was given about the severity of fetal anomaly and compatibility for life. Methods for termination of pregnancy were also discussed. After taking an informed, written consent and documentations for termination, the procedure was performed in patients with congenital anomaly requiring termination of pregnancy based on parity and period of gestation.

\section{RESULTS}

Out of a total 1879 deliveries, during the study period 39 fetuses with congenital anomalies were identified. Incidence of malformations being $2.1 \%$. The commonest congenital anomalies involved central nervous system (54\%) (Table 4).

Table 1: Distribution of patients according to age.

\begin{tabular}{|lll|}
\hline Age (in years) & Total cases- 39 & Percentage \\
\hline $\mathbf{2 0 - 2 5}$ & 1 & 3 \\
\hline $\mathbf{2 6 - 3 0}$ & 7 & 18 \\
\hline $\mathbf{3 1 - 3 5}$ & 31 & 79 \\
\hline
\end{tabular}

Table 2: Distribution of patients according to parity.

\begin{tabular}{|lll|}
\hline Parity & Total cases- 39 & Percentage \\
\hline Primigravida & 18 & 46 \\
\hline $2^{\text {nd }}$ gravida & 7 & 18 \\
\hline $3^{\text {rd }}$ gravida & 11 & 28 \\
\hline $\mathbf{4}^{\text {th }}$ or more & 3 & 8 \\
\hline
\end{tabular}

Table 3: Presence of foetal soft markers.

\begin{tabular}{|l|l|}
\hline Soft marker in USG & $\begin{array}{l}\text { Interpretation of } \\
\text { anomalies }\end{array}$ \\
\hline NT scan & 25 \\
\hline Choroid plexus cyst & 3 \\
\hline Echogenic bowel & 0 \\
\hline Short femur & 5 \\
\hline Single umbilical artery & 2 \\
\hline Echogenic focus in ventricle & 1 \\
\hline Renal pelvis dilatation & 1 \\
\hline
\end{tabular}

Table 4: Gross distribution of anomalies.

\begin{tabular}{|c|c|c|}
\hline System & Total cases- 39 & Percentage \\
\hline Craniospinal & 21 & 54 \\
\hline Cardiovascular & 2 & 5 \\
\hline Renal & 1 & 3 \\
\hline Abdominal & 1 & 2 \\
\hline Musculoskeletal & 13 & 33 \\
\hline $\begin{array}{l}\text { Multiple congenital } \\
\text { anomalies }\end{array}$ & 1 & 3 \\
\hline \multicolumn{3}{|c|}{ A: Distribution of anomalies- craniospinal } \\
\hline Meningomyelocele & 10 & 47 \\
\hline Spina bifida & 6 & 29 \\
\hline Acrania & 1 & 5 \\
\hline Anencephaly & 4 & 19 \\
\hline \multicolumn{3}{|c|}{ B: Distribution of anomalies- abdominal wall defects } \\
\hline Imperforate anus & 0 & 0 \\
\hline Gastroschisis & 1 & 100 \\
\hline \multicolumn{3}{|c|}{ C: Distribution of anomalies- cardiovascular } \\
\hline VSD & 1 & 50 \\
\hline PDA & 0 & 0 \\
\hline $\begin{array}{l}\text { Complex cardiac } \\
\text { anomaly }\end{array}$ & 1 & 50 \\
\hline \multicolumn{3}{|c|}{ D: Distribution of anomalies- renal } \\
\hline Bilateral hydronephrosis & 1 & 100 \\
\hline Renal agenesis & 0 & 0 \\
\hline \multicolumn{3}{|c|}{ E: Distribution of anomalies- musculoskeletal } \\
\hline Cleft lip & 5 & 38 \\
\hline Cleft palate & 4 & 31 \\
\hline Cleft lip and palate & 4 & 31 \\
\hline Limb defects & 0 & 0 \\
\hline Polydactyly & 0 & 0 \\
\hline
\end{tabular}

Table 5: Gestational age at termination.

\begin{tabular}{|lll|}
\hline Gestational age & Total cases- 39 & Percentage \\
\hline $\begin{array}{l}13 \text { weeks + } 1 \text { day to } \\
15 \text { weeks }\end{array}$ & 9 & 23 \\
\hline $\begin{array}{l}15 \text { weeks + 1 day to } \\
17 \text { weeks }\end{array}$ & 5 & 13 \\
\hline $\begin{array}{l}17 \text { weeks + 1 day to } \\
19 \text { weeks }\end{array}$ & 16 & 41 \\
\hline $\begin{array}{l}19 \text { weeks + 1 day to } \\
21 \text { weeks }\end{array}$ & 9 & 23 \\
\hline
\end{tabular}


The second most common type of anomaly involved the musculoskeletal system (33\%) (Table 4). Analysing the ages of the women who underwent termination $79 \%$ were in the age group of 30 to 35 years and $18 \%$ were in the age group of 25-30 years (Table 1). Primigravida women were $18 \%$ and the second highest group of women with anomalies were $3^{\text {rd }}$ gravida (Table 2).

Table 6: Risk factors.

\begin{tabular}{|ll|}
\hline Risk factor & Total cases- 39 \\
\hline Consanguinity & 12 \\
\hline Age $>\mathbf{3 0}$ years & 7 \\
\hline History of intrauterine foetal death & 1 \\
\hline Abortions & 9 \\
\hline Maternal diabetes & 13 \\
\hline Sibling with malformations & 1 \\
\hline Infections & 2 \\
\hline Anaemia & 11 \\
\hline Hypothyroidism & 8 \\
\hline Twins & 0 \\
\hline
\end{tabular}

Table 7: Method of termination.

\begin{tabular}{|lll|}
\hline Termination & Total cases- 39 & Percentage \\
\hline $\begin{array}{l}\text { Mifepristone }+ \\
\text { Misoprostol }\end{array}$ & 33 & 85 \\
\hline $\begin{array}{l}\text { Spontaneous } \\
\text { expulsion }\end{array}$ & 2 & 5 \\
\hline $\begin{array}{l}\text { Dilatation and } \\
\text { suction evacuation }\end{array}$ & 4 & 10 \\
\hline
\end{tabular}

Table 8: Sex of the foetus ( 15 weeks of gestation or more).

\begin{tabular}{|lll|}
\hline Sex & Total cases- 39 & Percentage \\
\hline Boy & 12 & 40 \\
\hline Girl & 18 & 60 \\
\hline
\end{tabular}

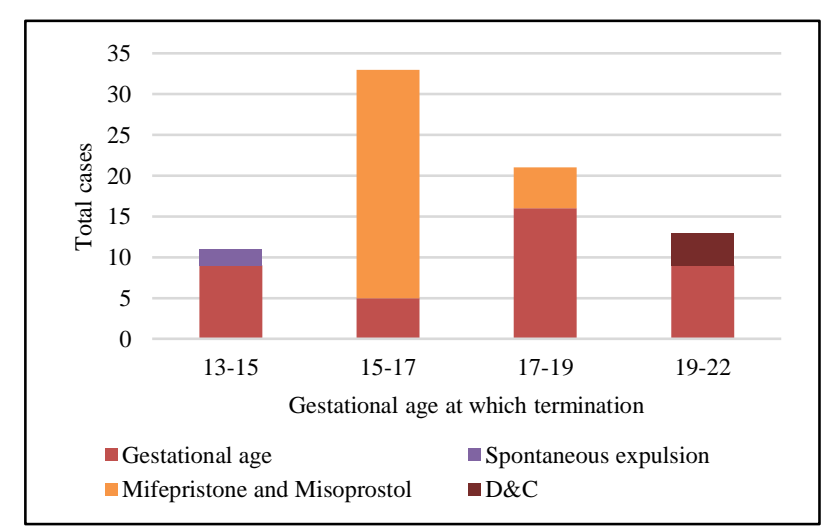

Figure 1: Gestational age and their method of termination.

About $31 \%$ of women had a history of consanguinity (Table 6). About $23 \%$ had history of previous miscarriage (Table 6). Congenital anomalies were detected before 22 weeks of gestation. Most of the anomalies were picked up only during the anomaly scan between $17-20$ weeks (64\%) (Table 5) as many of the women did not have their NT scans (11-13 weeks + 6 days). Most common risk factors identified were maternal diabetes $33 \%$, anemia $28 \%$ and hypothyroidism $8 \%$ (Table 6).

Perinatal mortality occurs due to congenital anomalies. Most of the congenital anomalies detected are associated with maternal contributing factors and have a role in contributing to perinatal mortality if identified late in gestation.

\section{DISCUSSION}

In this current study we analysed mid trimester termination of pregnancies for fetuses with congenital malformations. USG was the main modality used for diagnosis of structural fetal anomalies. Couples were explained about the fetal anomalies and its prognosis. Decision for pregnancy termination taken after written valid consent.

Anomaly scan performed at 18-22 weeks of gestational age is the investigation of choice to pick up anomalies. Consanguinity is the single most important factor with increased risk of fetal congenital anomalies. ${ }^{7}$ Awareness regarding the consanguinity and genetic counselling are important to reduce fetal morbidity. Preconceptional counselling and folic acid supplementation helps to reduce the occurrence of neural tube defects. Invasive procedures such as chorionic villus sampling or amniocentesis are restricted to certain high-risk populations, like those having a family history of congenital anomalies.

Termination of pregnancy can be accomplished by both medical and surgical methods. Mifepristone and misoprostol were the common agents used to terminate pregnancy, with misoprostol being used either orally or vaginally. Termination by older medical methods (extra amniotic ethacridine lactate) has been related to maternal morbidity, but misoprostol is found to have less complication rates than other drugs.

In a study conducted in Maharashtra by Taksande et al showed an incidence of $1.9 \%$ of anomalies. ${ }^{8}$ Higher incidence of congenital anomalies was noted in mothers aged above 30 years in a study by Singh et al. ${ }^{9}$ In our study a majority $(85 \%)$ of the terminations were by medical methods as the anomalies were picked up mostly after 16 weeks of gestation.

\section{CONCLUSION}

In this study, most of the women who had anomalous fetuses had risk factors like consanguinity, gestational diabetes and previous history of miscarriages. Preconceptional screening and counselling will help in identifying high risk factors and appropriate counselling can be provided. Couples should be screened with karyotyping if genetic risk factors are present. 
Targeted scan must be done at 18-20 weeks and fetal echocardiogram between 22 to 24 weeks to exclude anomalies in all pregnant women. Once the fetal anomalies are diagnosed various management options have to be discussed with the parents in consultation with neonatologist, pediatric surgeon and neuro surgeon.

If parents are willing to continue the pregnancy with compatible fetal congenital anomalies then pregnancy may be continued. But if the congenital anomalies are incompatible with life then pregnancy should be terminated. This study was conducted to study the incidence of various spectrum of congenital anomalies, their socio- demographic characteristics and their methods of termination of pregnancy in the population visiting a tertiary care hospital.

Funding: No funding sources Conflict of interest: None declared

Ethical approval: The study was approved by the Institutional Ethics Committee Proposal No: 205/IHEC/November 2020, 27.11.2020

\section{REFERENCES}

1. ACOG practice bulletin number 77: screening for fetal chromosomal abnormalities. Obstet Gynecol. 2007;109:217-27.

2. Rosano A. Infant mortality and congenital anomalies from 1950 to 1994: an international perspective. J Epidemiol Community Health. 2000;54:660-6.
3. Women's NCCf, Health Cs. Antenatal care: routine care for the healthy pregnant woman. RCOG press; 2008.

4. Anderson N, Boswell O, Duff G. Prenatal sonography for the detection of fetal anomalies: results of a prospective study and comparison with prior series. AJR Am J Roentgenol. 1995;165:943-50.

5. Napolitano R, Thilaganathan B. Late termination of pregnancy and fetal reduction for fetal anomaly. Best Pract Res Clin Obstet Gynaecol. 2010;24(4):529-37.

6. Liu S. Relationship of prenatal diagnosis and pregnancy termination to overall infant mortality in Canada. JAMA. 2002;287:1561-7.

7. Agarwal SS, Singh U, Singh PS, Singh SS, Das V, Sharma A, et al. Prevalence and spectrum of congenital malformations in a prospective study at a teaching hospital. Indian J Med Res. 1991;94:413-9.

8. Taksande A, Vilhekar K, Chaturvedi P, Jain M. Congenital malformations at birth in central India: a rural medical college hospital based data. Indian $\mathbf{J}$ Hum Genet. 2010;16:159.

9. Singh A, Gupta RK. Pattern of congenital anomalies in new-born: a hospital based prospective study. JK Sci. 2009;1:34-6.

Cite this article as: Suriyanarayanan G, Kandasamy V, Ramachandran AC. A retrospective analysis of mid trimester termination of pregnancies for fetal congenital malformations at tertiary care hospital. Int J Reprod Contracept Obstet Gynecol 2021;10:4254-7. 